\title{
A Balanced Approach for Cannabidiol Use in Chronic Pain
}

\author{
Donovan A. Argueta ${ }^{1}$, Christopher M. Ventura ${ }^{1}$, Stacy Kiven ${ }^{1}$, Varun Sagi ${ }^{2}$ \\ and Kalpna Gupta ${ }^{1,2,3 *}$ \\ ${ }^{1}$ Hematology/Oncology, Department of Medicine, University of California, Irvine, Irvine, CA, United States, ${ }^{2}$ Vascular Biology \\ Center, Division of Hematology, Oncology and Transplantation, Department of Medicine, University of Minnesota, \\ Minneapolis, MN, United States, ${ }^{3}$ Southern California Institute for Research and Education, Long Beach VA Healthcare \\ System, Long Beach, CA, United States
}

\section{OPEN ACCESS}

Edited by: Rajeev K. Singla,

Sichuan University, China

Reviewed by: Ashok K. Dubey,

University of Delhi, India

Francisco Mendonça

Mendonça-Junior,

State University of Paraíba, Brazi

${ }^{*}$ Correspondence:

Kalpna Gupta

kalpnag@hs.uci.edu

Specialty section:

This article was submitted to

Neuropharmacology,

a section of the journal

Frontiers in Pharmacology

Received: 27 February 2020

Accepted: 14 April 2020

Published: 30 April 2020

Citation:

Argueta DA, Ventura CM, Kiven S,

Sagi V and Gupta K (2020) A Balanced

Approach for Cannabidiol Use in

Chronic Pain.

Front. Pharmacol. 11:561.

doi: 10.3389/fphar.2020.00561
Cannabidiol (CBD), the major non-psychoactive constituent of Cannabis sativa L., has gained traction as a potential treatment for intractable chronic pain in many conditions. Clinical evidence suggests that CBD provides therapeutic benefit in certain forms of epilepsy and imparts analgesia in certain conditions, and improves quality of life. CBD continues to be Schedule I or $\mathrm{V}$ on the list of controlled substances of the Drug Enforcement Agency of the United States. However, preparations labeled CBD are available publicly in stores and on the streets. However, use of CBD does not always resolve pain. CBD purchased freely entails the risk of adulteration by potentially hazardous chemicals. As well, CBD use by pregnant women is rising and poses a major healthhazard for future generations. In this mini-review, we present balanced and unbiased preclinical and clinical findings for the beneficial effects of CBD treatment on chronic pain and its deleterious effects on prenatal development.

Keywords: cannabidiol, CBD, cannabis, chronic pain, teratogenicity

\section{INTRODUCTION}

Cannabis and its components are being widely used for chronic pain, especially given the multifaceted and persistent nature of chronic pain in many conditions (Kalant, 2001). Cannabidiol (CBD), one of the major phytocannabinoids, has gained significant attraction because it is devoid of the psychoactive effects associated with tetrahydrocannabinol (THC), another major constituent of cannabis (Leweke et al., 2012). With the recent rescheduling (Schedule V) of CBD as Epidiolex for the treatment of Dravet and Lennox-Gastaut syndromes there has been a major shift in the view of these ancient molecules for their medicinal potential (Laux et al., 2019). Preclinical and clinical studies have indicated a potential benefit of CBD use in chronic pain associated with multiple conditions (Wade et al., 2003). However, increasing access to cannabis derived products especially CBD partly because of their approval for recreational and medicinal use in the United States poses risks with inadvertant side-effects from overuse, contamination with adulterants in preparation or harsh chemicals in the plant cultivation, and its teratogenicity in the offspring of users (Bonn-Miller et al., 2017; Young-Wolff et al., 2017; Rubin, 2019). In this mini-review we will evaluate literature discussing CBD use in treating intractable pain and the potential hazards of its overuse and/or misuse (see Figure 1). 


\section{CHRONIC PAIN IN THE UNITED STATES}

Chronic pain affects between 50 and 116 million American adults, a staggering number that surpasses those affected by heart disease, cancer, and diabetes combined (Committee on Advancing Pain Research Care and Education, 2011; Nahin, 2015; NIH, 2020). In addition, these reports conclude that chronic pain costs between $\$ 560$ and $\$ 635$ billion annually in both medical expenses and lost productivity. Although there have been some recent therapeutic advances, many patients with chronic pain develop tolerance to conventional medical treatments or suffer adverse effects from widely used prescription medications, such as non-steroidal antiinflammatory agents or opiates, that have high addictive potential (Labianca et al., 2012). As early as 2003, formulations containing CBD have been used in the clinic to study its efficacy in reducing pain when traditional treatment options have failed.

\section{RELIABILITY AND SAFETY OF CANNABIDIOL LABELED PRODUCTS}

Human use of Cannabis sativa L. for rituals and medicine dates back millennia, and it has made recent advances in treatment of varied conditions (Kalant, 2001; Whiting et al., 2015; Aviram and Samuelly-Leichtag, 2017; Ren et al., 2019). CBD is the major non-psychoactive constituent of cannabis and is also found in hemp, a subspecies of Cannabis sativa that does not produce psychoactive compounds in significant amounts (Pertwee, 2006; Hilderbrand, 2018). With the exception of Epidiolex, a Schedule $\mathrm{V}$ preparation, which is a pharmaceutical CBD extract from the plant, cannabis-derived CBD still remains a Schedule I substance according to the United States (US) Drug Enforcement Administration (Drug Enforcement Administration, 2018). However, the US Hemp Farming Act of 2018 legalized the cultivation and refinement of hemp and its constituents, thus beginning a trend of mass marketing for $\mathrm{CBD}$ products both legal and illegal (Hemp Production and the 2018 Farm Bill, 2019; Mead, 2019). In states where cannabis has been approved for recreational and/or medical use, there are efforts to equip dispensary staff with scientific knowledge to make evidencebased recommendations, but these efforts are limited and often overshadowed by anecdotal understanding of $\mathrm{CBD}$ and other cannabinoids (Haug et al., 2016; Piermarini and Viswanath, 2019). Of major concern, CBD-labeled products have flooded the markets, including, but not limited to, inhalants, bath salts, cookies, ointments, and liquids, for human use. Many forms tout medicinal value for claims that have not been scientifically evaluated. Reports indicate that the cannabinoid content in products purchased online were only accurate in 26 of the 84 products tested (Bonn-Miller et al., 2017). In a more recent report, safety of using unregulated CBD products has been questioned because, of 20 popular CBD products tested by CannaSafe, a cannabis-testing company in California, only 3 contained the contents claimed on the labels (Rubin, 2019). Of these, 2 products had no $\mathrm{CBD}$, and about half of the $\mathrm{CBD}$ products had less than $20 \%$ of the CBD content claimed. Additionally, toxic gases and solvents were reported in some of these CBD products. Thus, these unregulated products labeled CBD may be a serious health hazard. An urgent need is to regulate $\mathrm{CBD}$ products after reliable testing to prevent the inadvertent harmful effects of unidentified constituents of products labeled CBD.

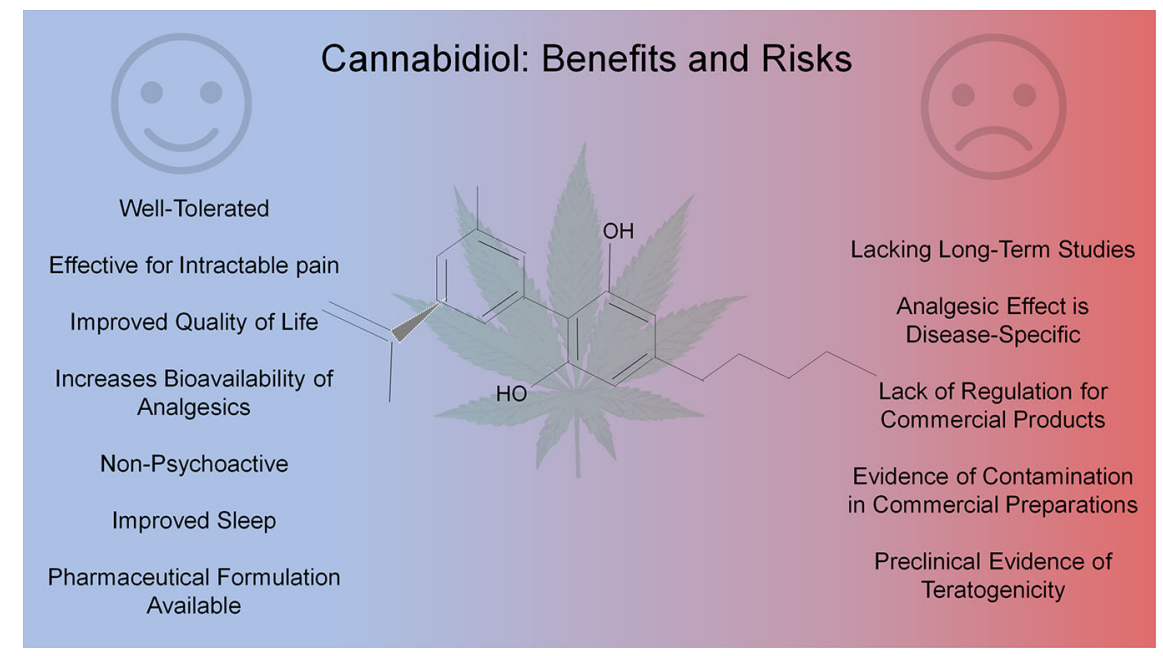

FIGURE 1 | Pros and cons of cannabidiol use in chronic pain. 


\section{CLINICAL OUTCOMES FOR CANNABIDIOL IN INTRACTABLE CHRONIC PAIN}

Since the early 2000s, clinical trials involving CBD for the treatment of chronic pain have shown effects ranging from placebo-equivalent to highly effective; many of these studies have been well-designed randomized, double-blinded, and placebo-controlled. In a mixed cohort of patients suffering from intractable pain due to multiple sclerosis, spinal cord injury, brachial plexus injury, and limb amputation, $\mathrm{CBD}$ treatment significantly reduced pain on a visual analog scale (Wade et al., 2003). However, these studies were often limited by small cohorts, and the varied disease states indicated that the beneficial effects of CBD are context dependent, which was illustrated in a study where treatment did not improve outcomes in patients suffering from Crohn's disease (Naftali et al., 2014). CBD was also seemingly effective in treatment of chronic pain associated with kidney transplantation and when given topically to patients suffering from peripheral neuropathy of their lower extremities (Cuñetti et al., 2018; Xu et al., 2019). As well, in patients with fibromyalgia, CBD treatment decreased pain by more than $30 \%$ in significantly more patients than placebo (Van De Donk et al., 2019). In studies of generalized chronic pain, CBD treatment did not significantly reduce measures of pain, however there was consistent improvement in patient-reported quality of life and quality of sleep (Notcutt et al., 2004; Capano et al., 2020). A New Zealand study on the safety of CBD treatment in 400 non-cancer chronic pain patients indicated its safety for prolonged use, which was accompanied by self-reported improvements in pain and quality of life (Gulbransen et al., 2020).

The majority of clinical studies for the treatment of intractable chronic pain with CBD typically utilized a combination of 1:1 CBD : THC, which was often in the form of the well-tolerated oromucosal spray Sativex (Nabiximols in the US) (Johnson et al., 2013; Sellers et al., 2013). Combination of the two often improved upon the deleterious and psychoactive effects of THC-only administration (Ueberall et al., 2019). The CBD : THC formulations were effective at reducing mean pain scores in chronic pain patients with multiple sclerosis, improved neurophysical measurements in response to noxious stimuli, reduced intractable chronic pain in advanced cancer, and improved refractory/neuropathic pain following failed spinal cord surgery (Rog et al., 2005; Conte et al., 2009; Johnson et al., 2010; Portenoy et al., 2012; Mondello et al., 2018). There is contradictory evidence that CBD : THC treatment does not always relieve chronic pain in patients with brachial plexus avulsion or advanced-cancer, as evidenced by studies in two-independent cohorts, thus indicating the heterogeneity in disease contexts for which cannabinoids may be effective; of note, although pain was not significantly improved, patients in these studies indicated an improved quality of life (Berman et al., 2004; Fallon et al., 2017; Lichtman et al., 2018). There is a demonstrated need to further understand the mode of action of CBD, and these results are promising, but efficacy of treatment must also be evaluated in other disease states that produce chronic pain such as diabetic neuropathy, rheumatic diseases, and sickle cell disease (Fitzcharles et al., 2016).

\section{MECHANISTIC INSIGHTS FOR CANNABIDIOL TREATMENT OF CHRONIC PAIN}

Few preclinical studies have been performed to evaluate the mechanism of analgesia for CBD treatment of chronic pain. Currently available studies rely on rodent and in vitro models but suggest molecular pathways that may be used to enhance CBD use in the clinic, or offer alternative approaches for higher efficacy. Evidence strongly supports that prolonged treatment (i.e. $>7$ days) with $\mathrm{CBD}$ alleviates chronic pain caused by chronic constriction injury of the sciatic nerve in rats and mice in a cannabinoid receptor-independent manner, and treatment is coincident with decreased hepatic cytochrome p450 and intestinal P-glycoprotein that may increase bioavailable circulating CBD (Costa et al., 2007; Comelli et al., 2008; Casey et al., 2017; Abraham et al., 2019). In vitro studies using human embryonic kidney cells reveal that at high doses CBD interacts with and selectively activates $\alpha_{1}$ - and $\alpha_{1} \beta$ glycine receptors, but these results have yet to be confirmed in vivo (Ahrens et al., 2009; Foadi et al., 2010). Alternatively, there is preliminary evidence that CBD may interact with $\alpha_{3}$-glycine receptors to reduce inflammation and hyperalgesia following simulated neuropathic pain by ligation of the L5 spinal nerve in adult Sprague-Dawley rats (Xiong et al., 2012). CBD also attenuates hyperalgesia in a mouse model of diabetic neuropathy with data suggesting that treatment reduced inflammatory milieu (Toth et al., 2010). Mouse models of pain associated with chemotherapy were simulated by Paclitaxel treatment, in which CBD produced an analgesic and anti-inflammatory effect via interactions with spinal cord 5-HT(1A) receptors (Ward et al., 2014; King et al., 2017). CBD also exerts analgesia in a 5-HT(1A)-dependent manner in streptozotocin-induced diabetic neuropathy in rats (Jesus et al., 2019). Similar to human studies, CBD did not produce complete analgesia in all models of chronic pain; in a cisplatin-induced mouse model of neuropathy, CBD attenuated but did not prevent hyperalgesia (Harris et al., 2016). Mechanical hyperalgesia was improved by $\mathrm{CBD}$ treatment following traumatic brain injury in mice, myofascial pain in rats, and 6-hydroxydopamine-induced mouse model of Parkinson's disease, however these studies require follow-up to inspect potential mechanisms of action (Belardo et al., 2019; Wong and Cairns, 2019; Crivelaro Do Nascimento et al., 2020). The preclinical work being done to disentangle the mechanisms of $\mathrm{CBD}$ in providing analgesic support in chronic pain is flourishing, but much remains in the wake of chronic disease and enhancing our understanding of the mechanisms at play.

\section{PUBLIC HEALTH HAZARDS AND TERATOGENICITY OF CANNABIS PRODUCTS}

Rising legalization and use of medical and recreational cannabis and CBD products raises significant health concerns with regards to both unregulated sources of these products discussed above as well as the health effects of prolonged usage. A recent multistate outbreak of coagulopathy from synthetic cannabinoids has been 
traced to the presence of long-acting anticoagulant rodenticides in "fake weed" (Arepally and Ortel, 2019). Furthermore, the US Centers for Disease Control and Prevention has increased awareness of the risks of severe pulmonary disease associated with use of electronic cigarette devices to "vape" tobacco and cannabis (Centers for Disease Control and Prevention, August $23,2019)$. The effects of long-term cannabinoid use are especially unclear in pregnant women, in whom potential teratogenic effects could have implications on future generations. Cannabis and $\mathrm{CBD}$ use are rising amongst pregnant women. An estimated $4 \%$ of pregnant women use cannabis, and in California, which recently legalized cannabis, about $20 \%$ in a cohort of 18 - to 24 year-old pregnant women reported using cannabis products in retrospective studies (Young-Wolff et al., 2017). These numbers are likely to rise as legalization continues throughout the US, and pharmaceutical strength preparations become available for several conditions, and because of the availability of CBD through stores and online sources (Millar et al., 2019). While several studies have focused on THC during pregnancy, investigation focused on the effects of CBD usage by pregnant women before, during, and/or after pregnancy are rare. Thus, there is an unmet need to examine the potential effects of CBD on embryonic and fetal development and the postnatal health of children exposed to CBD before birth. We will summarize here conclusions from both animal and human studies on some possible effects of CBD prenatally, perinatally, and postnatally.

CBD use during early gestation could pose a risk to critical pre-pregnancy and early pregnancy events. Successful pregnancy depends on reciprocal interactions between a competent embryo and a receptive endometrium in the mother. In early gestation $\mathrm{CBD}, \mathrm{THC}$, and cannabinol are thought to inhibit embryo implantation and placenta development by altering endometrial receptivity (Neradugomma et al., 2019). However, this effect has yet to be seen outside transformed human endometrial cell models. Exposure to CBD in chick embryos decreases the viability of the embryo by $50 \%$ to $80 \%$ dependent on CBD concentration and can delay embryonic development (Gustafsson and Jacobsson, 2019). Similar delays in embryonic development have been reported in zebrafish embryos exposed to CBD albeit without the decrease in viability (Valim Brigante et al., 2018). Teratogenicity of CBD has been reported in mice where prenatal exposure leads to an increase in craniofacial malformations and eye defects (Fish et al., 2019). Interestingly, these teratogenic effects are similar though milder than those observed for alcohol, THC, and the synthetic cannabinoids HU210 and CP55,940 countering the popular perception that CBD is an unequivocally safe alternative to THC and other cannabis constituents (Fish et al., 2019). In humans, retrospective metaanalysis has determined that in utero exposure to cannabis is associated with a decrease in birth weight and increased need for neonatal intensive care in infants (Gunn et al., 2016). This effect is likely due in part to the effects of CBD as low birth weights in mice offspring have been reported in response to prenatal CBD exposure exclusively (Fish et al., 2019). The observed teratogenic effects of CBD exposure may be due to the compound itself and/ or due to $\mathrm{CBD}$ working synergistically with other teratogenic compounds perhaps by enhancing permeability of xenobiotics through the human placental barrier thereby increasing fetal exposure (Feinshtein et al., 2013).

Effects on hormonal and reproductive function following maternal exposure to $\mathrm{CBD}$ have been reported in male mice. CBD exposed mice had lower testicular weights and lower overall levels of testosterone (Dalterio et al., 1984). These effects are in line with reports of hormonal and reproductive effects due to postnatal exposure to $\mathrm{CBD}$ or cannabis in rats and monkeys. Chronic doses of THC or CBD in rat suppress hepatic testosterone oxidation by selective inhibition of male-specific cytochrome p450 in the adult male rat (Narimatsu et al., 1988). Chronic doses of CBD in rat also cause a significant reduction in testosterone formation and a decrease in testicular enzyme activity (List et al., 1977). In both rhesus monkeys and rats, gonadal function is altered due to exposure to THC or CBD which leads to hormonal imbalance including a decrease in testosterone in male rats and an increase in follicle-stimulating hormone in male monkeys (Rosenkrantz and Esber, 1980). Together, these data suggest that CBD may influence spermatogenesis and libido in males.

Maternal exposure to $\mathrm{CBD}$ is also likely to cause neurochemical changes in the brain of the offspring. The $\alpha 1$ adrenergic and D2-dopaminergic receptors in the cerebral cortex and striatum of rats exposed prenatally to either CBD or THC exhibited smaller binding affinities for their respective ligands and hypothalamic dopamine levels in mice have been observed to be greatly depleted in CBD-exposed males as well (Dalterio et al., 1984; Walters and Carr, 1988). Overall, these studies suggest that prenatal exposure to $\mathrm{CBD}$ is likely to alter the production of testosterone, the function of the male gonads, and the receptor ligand interactions in the brain of offsprings.

\section{CONCLUSION}

Rising prevalence of the non-psychoactive cannabinoid CBD presents an opportunity for the treatment of intractable chronic pain for which primary treatments are insufficient or not possible. As depicted by the studies reviewed herein, the use of CBD is context-specific, and it should not be used indiscriminately (see Table 1). Preliminary mechanistic studies indicate conservation of function via modulation of hepatic cytochrome p450 leading to increased bioavailability of endogenous mediators of pain (i.e. serotonin) and exogenous analgesics (i.e. THC). Therefore, it is important to continue studies into the conditions for which $\mathrm{CBD}$ may be effective as a treatment via novel actionable targets. Simultaneously, the growing access to unregulated CBD products, which may be adulterated with potentially toxic compounds, requires regulation and education about $\mathrm{CBD}$ for its potential benefits and/or adverse effects in health and disease. This is especially the case in pregnant women, which raises the highest possible risk for the developing fetus and future offsprings. 
TABLE 1 | Consequence of Cannabidiol treatment in preclinical and clinical settings.

\begin{tabular}{|c|c|c|c|}
\hline Source & Species & Effect & References \\
\hline \multicolumn{4}{|c|}{ Beneficial Effects } \\
\hline $\begin{array}{l}\text { CBD } \\
\left({ }^{1} \text { Sigma) }\right.\end{array}$ & HEK cells & Activation of $\alpha 1$ and $\alpha 1 \beta$-glycine receptors & Ahrens et al., 2009¹ ; Foadi et al., 2010 \\
\hline $\begin{array}{l}\text { CBD } \\
\left({ }^{1} \text { Enecta Group; }\right. \\
\left.{ }^{2} \text { Cayman; }{ }^{3} \mathrm{NIH} ;{ }^{4} \mathrm{NS}\right)\end{array}$ & Mice & $\downarrow$ inflammation; $\downarrow$ hyperalgesia & $\begin{array}{l}\text { Belardo et al., 20191; }{ }^{4} \text { Crivelaro Do Nascimento et al., } \\
\text { 2020; (Toth et al., 2010) }{ }^{2} \text {; (Ward et al., 2014; King et al., } \\
\text { 2017); }{ }^{3} \text { (Harris et al., 2016); }\end{array}$ \\
\hline $\begin{array}{l}\text { CBD } \\
\left({ }^{1} \mathrm{NIH} ;{ }^{2} \mathrm{THC} \text { Pharm; }{ }^{3} \mathrm{GW}\right. \\
\left.\text { Pharma; }{ }^{\mathbf{4}} \text { Cayman; }{ }^{5} \mathrm{NS}\right)\end{array}$ & Rat & $\begin{array}{l}\downarrow \text { inflammation; } \downarrow \text { hyperalgesia; } \\
\downarrow \text { hepatic cytochrome p450 }\end{array}$ & $\begin{array}{l}\text { (Costa et al., 2007; Comelli et al., 2008; Casey et al., } \\
\text { 2017; Abraham et al., 2019) }{ }^{3} \text {; (Xiong et al., 2012) }{ }^{1} \text {; } \\
\text { (Jesus et al., 2019) } \text {; Wong and Cairns, 20194 }\end{array}$ \\
\hline $\begin{array}{l}\text { CBD } \\
\left({ }^{1} \text { Stanley Brothers; }\right. \\
{ }^{2} \text { Bedrocan International; } \\
{ }^{3} \text { Ananda Professional; }{ }^{4} \text { Tilray; } \\
\left.{ }^{5} \mathrm{NS}\right)\end{array}$ & Humans & $\begin{array}{l}\text { Patient-reported: } \downarrow \text { chronic pain; } \\
\uparrow \text { quality of life; } \uparrow \text { quality of sleep }\end{array}$ & $\begin{array}{l}\text { (Wade et al., 2003) }{ }^{5} \text {; (Cuñetti et al., 2018; Xu et al., } \\
\text { 2019); (Van De Donk et al., 2019) }{ }^{2} \text { (Notcutt et al., 2004; } \\
\text { Capano et al., 2020) }{ }^{5} \text {; (Gulbransen et al., 2020) }\end{array}$ \\
\hline $\begin{array}{l}1: 1 \\
\text { CBD : THC } \\
\text { (GW Pharma.) }\end{array}$ & Humans & $\begin{array}{l}\text { improved refractory/neuropathic pain; } \\
\text { Patient-reported } \downarrow \text { chronic pain; } \uparrow \text { quality of life; } \\
\text { Improved responses to noxious stimuli }\end{array}$ & $\begin{array}{l}\text { Johnson et al., 2013; Sellers et al., 2013; Ueberall et al., } \\
\text { 2019; (Rog et al., 2005; Conte et al., 2009; Johnson } \\
\text { et al., 2010; Portenoy et al., 2012; Mondello et al., 2018) } \\
\text { (Berman et al., 2004; Fallon et al., 2017; Lichtman et al., } \\
\text { 2018); NCT01424566; NCT01361607; NCT01262651; } \\
\text { NCT01606189; NCT01337089 }\end{array}$ \\
\hline \multicolumn{4}{|c|}{ Adverse Effects } \\
\hline $\begin{array}{l}\mathrm{CBD} \\
(\mathrm{NS})\end{array}$ & HES model cells & $\begin{array}{l}\text { Adversely impact embryo implantation; Delay } \\
\text { placenta development }\end{array}$ & Neradugomma et al., 2019 \\
\hline $\begin{array}{l}\text { CBD } \\
\text { (The Hebrew University) }\end{array}$ & $\begin{array}{l}\text { MCF7/P-gp, BeWo } \\
\text { and Jar cells }\end{array}$ & $\uparrow$ placental xenobiotic permeability & Feinshtein et al., 2013 \\
\hline $\begin{array}{l}\text { CBD } \\
\text { (BSPG Pharm.) }\end{array}$ & Zebrafish embryos & $\begin{array}{l}\text { Delay in embryo development; } \\
\uparrow \text { embryo activity }\end{array}$ & Valim Brigante et al., 2018 \\
\hline $\begin{array}{l}\mathrm{CBD} \\
\text { (Tocris) }\end{array}$ & Chick embryos & $\begin{array}{l}50-80 \% \downarrow \text { in embryo viability; } \\
\text { Delay in embryo development }\end{array}$ & Gustafsson and Jacobsson, 2019 \\
\hline $\begin{array}{l}\text { CBD } \\
\text { (Cayman Chemical) }\end{array}$ & Mice offspring & $\begin{array}{l}\uparrow \text { Eye defects; } \downarrow \text { birth weight; } \\
\text { Abnormal craniofacies; } \downarrow \text { testicular weight; } \\
\downarrow \text { testicular testosterone levels } \\
\downarrow \text { hypothalamic dopamine levels }\end{array}$ & Dalterio et al., 1984; Fish et al., 2019 \\
\hline $\begin{array}{l}\mathrm{CBD} \\
\left({ }^{\mathbf{1}} \mathrm{NIH} ;{ }^{2} \text { Kyushu University) }\right.\end{array}$ & Rat offspring & $\begin{array}{l}\downarrow \text { hepatic cytochrome p450 } \\
\downarrow \text { testicular testosterone levels } \\
\downarrow \text { binding affinities for } \alpha 1 \text {-adrenergic and D2- } \\
\text { dopaminergic receptors }\end{array}$ & $\begin{array}{l}\text { List et al., } 1977^{1} \text {; Rosenkrantz and Esber, } 1980^{1} \text {; } \\
\text { Narimatsu et al., } 1988^{2} \text {; Walters and Carr, } 1988^{1}\end{array}$ \\
\hline $\begin{array}{l}\mathrm{CBD} \\
(\mathrm{NIH})\end{array}$ & Rhesus monkeys & $\begin{array}{l}\uparrow \text { follicle-stimulating hormone; } \\
\text { hormonal imbalance }\end{array}$ & Rosenkrantz and Esber, 1980 \\
\hline $\begin{array}{l}\text { Cannabis } \\
\text { (NS) }\end{array}$ & Humans & $\begin{array}{l}\downarrow \text { birth weight } \\
\uparrow \text { need for neonatal intensive care }\end{array}$ & Gunn et al., 2016 \\
\hline
\end{tabular}

CBD, cannabidiol; THC, tetrahydrocannabinol; HEK cells, human embryonic kidney cells; HES cells, human endometrial stroma cells; JAr cells, human choriocarcinoma cells; BeWo cells,

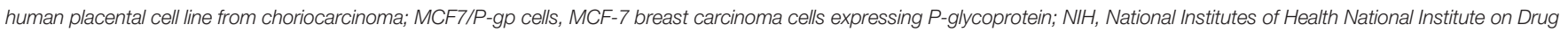

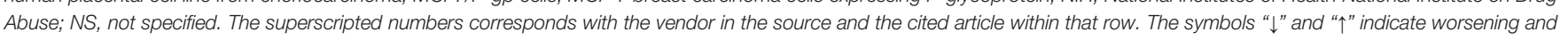
improvement of outcomes, respectively.

Unfortunately, efforts to discuss the dangers of CBD use have been severely lacking and require immediate attention to prevent the irreparable harm to the masses from the tsunami of CBD products.

\section{AUTHOR CONTRIBUTIONS}

DA wrote the manuscript and prepared it for communication. CV co-wrote the manuscript and prepared the table. SK reviewed the contents and prepared the figure. VS contributed to the structure and edited the manuscript. KG defined the content, searched the literature, supervised the writing, and edited the manuscript.

\section{FUNDING}

We gratefully acknowledge funding from NIH grants U18 EB029354 and HL147562 to KG. The content is solely the responsibility of the authors and does not necessarily represent the official views of the National Institutes of Health.

\section{ACKNOWLEDGMENTS}

We acknowledge creative commons for their licensing of images used in the figure. All images are freely available through pixabay.com under creative commons license. 


\section{REFERENCES}

Abraham, A. D., Leung, E. J. Y., Wong, B. A., Rivera, Z. M. G., Kruse, L. C., Clark, J. J., et al. (2019). Orally Consumed Cannabinoids Provide Long-Lasting Relief of Allodynia in a Mouse Model of Chronic Neuropathic Pain. Neuropsychopharmacology. doi: 10.1038/S41386-019-0585-3

Ahrens, J., Demir, R., Leuwer, M., De La Roche, J., Krampfl, K., Foadi, N., et al. (2009). the Nonpsychotropic Cannabinoid Cannabidiol Modulates and Directly Activates Alpha-1 and Alpha-1-Beta Glycine Receptor Function. Pharmacology 83 (4), 217-222. doi: 10.1159/000201556

Arepally, G. M., and Ortel, T. L. (2019). Bad Weed: Synthetic CannabinoidAssociated Coagulopathy. Blood 133 (9), 902-905. doi: 10.1182/Blood-2018-11876839

Aviram, J., and Samuelly-Leichtag, G. (2017). Efficacy of Cannabis-Based Medicines for Pain Management: a Systematic Review and Meta-Analysis of Randomized Controlled Trials. Pain Physician 20 (6), E755-E796.

Belardo, C., Iannotta, M., Boccella, S., Rubino, R. C., Ricciardi, F., Infantino, R., et al. (2019). Oral Cannabidiol Prevents Allodynia and Neurological Dysfunctions in a Mouse Model of Mild Traumatic Brain Injury. Front. Pharmacol. 10, 352. doi: 10.3389/Fphar.2019.00352

Berman, J. S., Symonds, C., and Birch, R. (2004). Efficacy of Two Cannabis Based Medicinal Extracts for Relief of Central Neuropathic Pain From Brachial Plexus Avulsion: Results of a Randomised Controlled Trial. Pain 112 (3), 299-306. doi: 10.1016/J.Pain.2004.09.013

Bonn-Miller, M. O., Loflin, M. J. E., Thomas, B. F., Marcu, J. P., Hyke, T., and Vandrey, R. (2017). Labeling Accuracy of Cannabidiol Extracts Sold Online. JAMA 318 (17), 1708-1709. doi: 10.1001/Jama.2017.11909

Capano, A., Weaver, R., and Burkman, E. (2020). Evaluation of the Effects of CBD Hemp Extract on Opioid Use and Quality of Life Indicators in Chronic Pain Patients: a Prospective Cohort Study. Postgrad. Med. 132 (1), 56-61. doi: $10.1080 / 00325481.2019 .1685298$

Casey, S. L., Atwal, N., and Vaughan, C. W. (2017). Cannabis Constituent Synergy in a Mouse Neuropathic Pain Model. Pain 158 (12), 2452-2460. doi: 10.1097/ J.Pain.0000000000001051

Comelli, F., Giagnoni, G., Bettoni, I., Colleoni, M., and Costa, B. (2008). Antihyperalgesic Effect of a Cannabis Sativa Extract in a Rat Model of Neuropathic Pain: Mechanisms Involved. Phytother. Res. 22 (8), 1017-1024. doi: 10.1002/Ptr.2401

Committee on Advancing Pain Research Care and Education and B. O. H. S. P., I. Stitute of Medicine (2011). a Call for Cultural Transformation of Attitudes Toward Pain and Its Prevention and Management. J. Pain Palliat Care Pharmacother. 25 (4), 365-369. doi: 10.3109/15360288.2011.621516

Conte, A., Bettolo, C. M., Onesti, E., Frasca, V., Iacovelli, E., Gilio, F., et al. (2009). Cannabinoid-Induced Effects on the Nociceptive System: a Neurophysiological Study in Patients With Secondary Progressive Multiple Sclerosis. Eur. J. Pain 13 (5), 472-477. doi: 10.1016/J.Ejpain.2008.05.014

Costa, B., Trovato, A. E., Comelli, F., Giagnoni, G., and Colleoni, M. (2007). the Non-Psychoactive Cannabis Constituent Cannabidiol Is an Orally Effective Therapeutic Agent in Rat Chronic Inflammatory and Neuropathic Pain. Eur. J. Pharmacol. 556 (1-3), 75-83. doi: 10.1016/J.Ejphar.2006.11.006

Crivelaro Do Nascimento, G., Ferrari, D. P., Guimaraes, F. S., Del Bel, E. A., Bortolanza, M., and Ferreira-Junior, N. C. (2020). Cannabidiol Increases the Nociceptive Threshold in a Preclinical Model of Parkinson's Disease. Neuropharmacology 163, 107808. doi: 10.1016/J.Neuropharm.2019.107808

Cuñetti, L., Manzo, L., Peyraube, R., Arnaiz, J., Curi, L., and Orihuela, S. (2018). Chronic Pain Treatment With Cannabidiol in Kidney Transplant Patients in Uruguay. Transplant. Proc. 50 (2), 461-464. doi: 10.1016/ J.Transproceed.2017.12.042

Dalterio, S., Steger, R., Mayfield, D., and Bartke, A. (1984). Early Cannabinoid Exposure Influences Neuroendocrine and Reproductive Functions in Mice: II. Postnatal Effects. Pharmacol. Biochem. Behav. 20 (1), 115-123. doi: 10.1016/ 0091-3057(84)90111-4

Drug Enforcement Administration, D. P. O. J. (2018) Schedules of Controlled Substances: Placement in Schedule V of Certain FDA-Approved Drugs Containing Cannabidiol; Corresponding Change to Permit Requirements. Final Order. Fed Regist. 83 (189), 48950-48953.

Fallon, M. T., Albert Lux, E., Mcquade, R., Rossetti, S., Sanchez, R., Sun, W., et al. (2017). Sativex Oromucosal Spray as Adjunctive Therapy in Advanced Cancer
Patients With Chronic Pain Unalleviated by Optimized Opioid Therapy: Two Double-Blind, Randomized, Placebo-Controlled Phase 3 Studies. Br. J. Pain 11 (3), 119-133. doi: 10.1177/2049463717710042

Feinshtein, V., Erez, O., Ben-Zvi, Z., Eshkoli, T., Sheizaf, B., Sheiner, E., et al. (2013). Cannabidiol Enhances Xenobiotic Permeability Through the Human Placental Barrier by Direct Inhibition of Breast Cancer Resistance Protein: an Ex Vivo Study. Am. J. Obstet. Gynecol. 209 (6), 573.E571-573.E515. doi: 10.1016/J.Ajog.2013.08.005

Fish, E. W., Murdaugh, L. B., Zhang, C., Boschen, K. E., Boa-Amponsem, O. Mendoza-Romero, H. N., et al. (2019). Cannabinoids Exacerbate Alcohol Teratogenesis by a CB1-Hedgehog Interaction. Sci. Rep. 9 (1), 16057. doi: 10.1038/S41598-019-52336-W

Fitzcharles, M. A., Baerwald, C., Ablin, J., and Häuser, W. (2016). Efficacy, Tolerability and Safety of Cannabinoids in Chronic Pain Associated With Rheumatic Diseases (Fibromyalgia Syndrome, Back Pain, Osteoarthritis, Rheumatoid Arthritis): a Systematic Review of Randomized Controlled Trials. Schmerz 30 (1), 47-61. doi: 10.1007/S00482-015-0084-3

Foadi, N., Leuwer, M., Demir, R., Dengler, R., Buchholz, V., De La Roche, J., et al. (2010). Lack of Positive Allosteric Modulation of Mutated Alpha(1)S267I Glycine Receptors by Cannabinoids. Naunyn Schmiedebergs Arch. Pharmacol. 381 (5), 477-482. doi: 10.1007/S00210-010-0506-9

Gulbransen, G., Xu, W., and Arroll, B. (2020). Cannabidiol Prescription in Clinical Practice: an Audit on the First 400 Patients in New Zealand. BJGP Open. doi: 10.3399/Bjgpopen20x101010

Gunn, J. K., Rosales, C. B., Center, K. E., Nuñez, A., Gibson, S. J., Christ, C., et al. (2016). Prenatal Exposure to Cannabis and Maternal and Child Health Outcomes: a Systematic Review and Meta-Analysis. BMJ Open 6 (4), E009986. doi: 10.1136/Bmjopen-2015-009986

Gustafsson, S. B., and Jacobsson, S. O. P. (2019). Effects of Cannabinoids on the Development of Chick Embryos in Ovo. Sci. Rep. 9 (1), 13486. doi: 10.1038/ S41598-019-50004-7

Harris, H. M., Sufka, K. J., Gul, W., and Elsohly, M. A. (2016). Effects of Delta-9Tetrahydrocannabinol and Cannabidiol on Cisplatin-Induced Neuropathy in Mice. Planta Med. 82 (13), 1169-1172. doi: 10.1055/S-0042-106303

Haug, N. A., Kieschnick, D., Sottile, J. E., Babson, K. A., Vandrey, R., and BonnMiller, M. O. (2016). Training and Practices of Cannabis Dispensary Staff. Cannabis Cannabinoid Res. 1 (1), 244-251. doi: 10.1089/Can.2016.0024

Hemp Production and the 2018 Farm Bill (2019).

Hilderbrand, R. L. (2018). Hemp \& Cannabidiol: What Is a Medicine? Mo. Med. 115 (4), 306-309.

Jesus, C. H. A., Redivo, D. D. B., Gasparin, A. T., Sotomaior, B. B., De Carvalho, M. C., Genaro, K., et al. (2019). Cannabidiol Attenuates Mechanical Allodynia in Streptozotocin-Induced Diabetic Rats Via Serotonergic System Activation Through 5-HT1A Receptors. Brain Res. 1715, 156-164. doi: 10.1016/ J.Brainres.2019.03.014

Johnson, J. R., Burnell-Nugent, M., Lossignol, D., Ganae-Motan, E. D., Potts, R., and Fallon, M. T. (2010). Multicenter, Double-Blind, Randomized, PlaceboControlled, Parallel-Group Study of the Efficacy, Safety, and Tolerability of THC:CBD Extract and THC Extract in Patients With Intractable CancerRelated Pain. J. Pain Symptom Manage 39 (2), 167-179. doi: 10.1016/ J.Jpainsymman.2009.06.008

Johnson, J. R., Lossignol, D., Burnell-Nugent, M., and Fallon, M. T. (2013). an Open-Label Extension Study to Investigate the Long-Term Safety and Tolerability of THC/CBD Oromucosal Spray and Oromucosal THC Spray in Patients With Terminal Cancer-Related Pain Refractory to Strong Opioid Analgesics. J. Pain Symptom Manage 46 (2), 207-218. doi: 10.1016/ J.Jpainsymman.2012.07.014

Kalant, H. (2001). Medicinal Use of Cannabis: History and Current Status. Pain Res. Manag. 6 (2), 80-91. doi: 10.1155/2001/469629

King, K. M., Myers, A. M., Soroka-Monzo, A. J., Tuma, R. F., Tallarida, R. J., Walker, E. A., et al. (2017). Single and Combined Effects of $\Delta$. Br. J. Pharmacol. 174 (17), 2832-2841. doi: 10.1111/Bph.13887

Labianca, R., Sarzi-Puttini, P., Zuccaro, S. M., Cherubino, P., Vellucci, R., and Fornasari, D. (2012). Adverse Effects Associated With Non-Opioid and Opioid Treatment in Patients With Chronic Pain. Clin. Drug Invest. 32 Suppl 1, 53-63. doi: 10.2165/11630080-000000000-00000

Laux, L. C., Bebin, E. M., Checketts, D., Chez, M., Flamini, R., Marsh, E. D., et al. (2019). Long-Term Safety and Efficacy of Cannabidiol in Children and Adults 
With Treatment Resistant Lennox-Gastaut Syndrome or Dravet Syndrome: Expanded Access Program Results. Epilepsy Res. 154, 13-20. doi: 10.1016/ J.Eplepsyres.2019.03.015

Leweke, F. M., Piomelli, D., Pahlisch, F., Muhl, D., Gerth, C. W., Hoyer, C., et al. (2012). Cannabidiol Enhances Anandamide Signaling and Alleviates Psychotic Symptoms of Schizophrenia. Transl. Psychiatry 2, E94. doi: 10.1038/ Tp.2012.15

Lichtman, A. H., Lux, E. A., Mcquade, R., Rossetti, S., Sanchez, R., Sun, W., et al. (2018). Results of a Double-Blind, Randomized, Placebo-Controlled Study of Nabiximols Oromucosal Spray as an Adjunctive Therapy in Advanced Cancer Patients With Chronic Uncontrolled Pain. J. Pain Symptom Manage 55 (2), 179-188.E171. doi: 10.1016/J.Jpainsymman.2017.09.001

List, A., Nazar, B., Nyquist, S., and Harclerode, J. (1977). the Effects of Delta9Tetrahydrocannabinol and Cannabidiol on the Metabolism of Gonadal Steroids in the Rat. Drug Metab. Dispos. 5 (3), 268-272.

Mead, A. (2019). Legal and Regulatory Issues Governing Cannabis and CannabisDerived Products in the United States. Front. Plant Sci. 10, 697. doi: 10.3389/ Fpls.2019.00697

Millar, S. A., Stone, N. L., Bellman, Z. D., Yates, A. S., England, T. J., and O'Sullivan, S. E. (2019). a Systematic Review of Cannabidiol Dosing in Clinical Populations. Br. J. Clin. Pharmacol. 85 (9), 1888-1900. doi: 10.1111/Bcp.14038

Mondello, E., Quattrone, D., Cardia, L., Bova, G., Mallamace, R., Barbagallo, A. A., et al. (2018). Cannabinoids and Spinal Cord Stimulation for the Treatment of Failed Back Surgery Syndrome Refractory Pain. J. Pain Res. 11, 1761-1767. doi: $10.2147 /$ JPR.S166617

Naftali, T., Mechulam, R., Lev, L. B., and Konikoff, F. M. (2014). Cannabis for Inflammatory Bowel Disease. Dig. Dis. 32 (4), 468-474. doi: 10.1159/000358155

Nahin, R. L. (2015). Estimates of Pain Prevalence and Severity in Adults: United States 2012. J. Pain 16 (8), 769-780. doi: 10.1016/J.Jpain.2015.05.002

Narimatsu, S., Watanabe, K., Yamamoto, I., and Yoshimura, H. (1988). Mechanism for Inhibitory Effect of Cannabidiol on Microsomal Testosterone Oxidation in Male Rat Liver. Drug Metab. Dispos. 16 (6), 880-889.

Neradugomma, N. K., Drafton, K., Mor, G. G., and Mao, Q. (2019). MarijuanaDerived Cannabinoids Inhibit Uterine Endometrial Stromal Cell Decidualization and Compromise Trophoblast-Endometrium Cross-Talk. Reprod. Toxicol. 87, 100-107. doi: 10.1016/J.Reprotox.2019.05.064

NIH (2020). NIH HEAL Initiative Research Plan. Retrieved From https://Heal. Nih.Gov/About/Research-Plan\#References. Accessed April 1, 2020.

Notcutt, W., Price, M., Miller, R., Newport, S., Phillips, C., Simmons, S., et al. (2004). Initial Experiences With Medicinal Extracts of Cannabis for Chronic Pain: Results From 34 ' $\mathrm{N}$ of 1' Studies. Anaesthesia 59 (5), 440-452. doi: 10.1111/J.1365-2044.2004.03674.X

Pertwee, R. G. (2006). Cannabinoid Pharmacology: the First 66 Years. Br. J. Pharmacol. 147 Suppl 1, S163-S171. doi: 10.1038/Sj.Bjp.0706406

Piermarini, C., and Viswanath, O. (2019). CBD as the New Medicine in the Pain Provider's Armamentarium. Pain Ther. 8 (1), 157-158. doi: 10.1007/S40122-019-0117-1

Portenoy, R. K., Ganae-Motan, E. D., Allende, S., Yanagihara, R., Shaiova, L., Weinstein, S., et al. (2012). Nabiximols for Opioid-Treated Cancer Patients With Poorly-Controlled Chronic Pain: a Randomized, Placebo-Controlled, Graded-Dose Trial. J. Pain 13 (5), 438-449. doi: 10.1016/J.Jpain.2012.01.003

Ren, M., Tang, Z., Wu, X., Spengler, R., Jiang, H., Yang, Y., et al. (2019). the Origins of Cannabis Smoking: Chemical Residue Evidence From the First Millennium BCE in the Pamirs. Sci. Adv. 5 (6), Eaaw1391. doi: 10.1126/ Sciadv.Aaw1391

Rog, D. J., Nurmikko, T. J., Friede, T., and Young, C. A. (2005). Randomized, Controlled Trial of Cannabis-Based Medicine in Central Pain in Multiple Sclerosis. Neurology 65 (6), 812-819. doi: 10.1212/01.Wnl.0000176753.45410.8b

Rosenkrantz, H., and Esber, H. J. (1980). Cannabinoid-Induced Hormone Changes in Monkeys and Rats. J. Toxicol. Environ. Health 6 (2), 297-313. doi: $10.1080 / 15287398009529853$

Rubin, R. (2019). Cannabidiol Products Are Everywhere, But Should People Be Using Them? JAMA. 322 (22), 2156-2158. doi: 10.1001/Jama.2019.17361

Sellers, E. M., Schoedel, K., Bartlett, C., Romach, M., Russo, E. B., Stott, C. G., et al. (2013). A Multiple-Dose, Randomized, Double-Blind, Placebo-Controlled,
Parallel-Group QT/Qtc Study to Evaluate the Electrophysiologic Effects of THC/CBD Spray. Clin. Pharmacol. Drug Dev. 2 (3), 285-294. doi: 10.1002/ Cpdd. 36

Toth, C. C., Jedrzejewski, N. M., Ellis, C. L., and Frey, W. H. (2010). CannabinoidMediated Modulation of Neuropathic Pain and Microglial Accumulation in a Model of Murine Type I Diabetic Peripheral Neuropathic Pain. Mol. Pain 6, 16. doi: 10.1186/1744-8069-6-16

Ueberall, M. A., Essner, U., and Mueller-Schwefe, G. H. (2019). Effectiveness and Tolerability of THC:CBD Oromucosal Spray as Add-On Measure in Patients With Severe Chronic Pain: Analysis of 12-Week Open-Label Real-World Data Provided by the German Pain E-Registry. J. Pain Res. 12, 1577-1604. doi: 10.2147/JPR.S192174

Valim Brigante, T. A., Abe, F. R., Zuardi, A. W., Hallak, J. E. C., Crippa, J. A. S., and De Oliveira, D. P. (2018). Cannabidiol Did Not Induce Teratogenicity or Neurotoxicity in Exposed Zebrafish Embryos. Chem. Biol. Interact. 291, 81-86. doi: 10.1016/J.Cbi.2018.06.008

Van De Donk, T., Niesters, M., Kowal, M. A., Olofsen, E., Dahan, A., and Van Velzen, M. (2019). An Experimental Randomized Study on the Analgesic Effects of Pharmaceutical-Grade Cannabis in Chronic Pain Patients With Fibromyalgia. Pain 160 (4), 860-869. doi: 10.1097/J.Pain.0000000000001464

Wade, D. T., Robson, P., House, H., Makela, P., and Aram, J. (2003). A Preliminary Controlled Study to Determine Whether Whole-Plant Cannabis Extracts Can Improve Intractable Neurogenic Symptoms. Clin. Rehabil. 17 (1), 21-29. doi: $10.1191 / 0269215503$ cr581oa

Walters, D. E., and Carr, L. A. (1988). Perinatal Exposure to Cannabinoids Alters Neurochemical Development in Rat Brain. Pharmacol. Biochem. Behav. 29 (1), 213-216. doi: 10.1016/0091-3057(88)90300-0

Ward, S. J., Mcallister, S. D., Kawamura, R., Murase, R., Neelakantan, H., and Walker, E. A. (2014). Cannabidiol Inhibits Paclitaxel-Induced Neuropathic Pain Through 5-HT(1A) Receptors Without Diminishing Nervous System Function or Chemotherapy Efficacy. Br. J. Pharmacol. 171 (3), 636-645. doi: 10.1111/Bph.12439

Whiting, P. F., Wolff, R. F., Deshpande, S., Di Nisio, M., Duffy, S., Hernandez, A. V., et al. (2015). Cannabinoids for Medical Use: a Systematic Review and MetaAnalysis. Jama 313 (24), 2456-2473. doi: 10.1001/Jama.2015.6358

Wong, H., and Cairns, B. E. (2019). Cannabidiol, Cannabinol and Their Combinations Act as Peripheral Analgesics in a Rat Model of Myofascial Pain. Arch. Biol. 104, 33-39. doi: 10.1016/J.Archoralbio.2019.05.028

Xiong, W., Cui, T., Cheng, K., Yang, F., Chen, S. R., Willenbring, D., et al. (2012). Cannabinoids Suppress Inflammatory and Neuropathic Pain by Targeting A3 Glycine Receptors. J. Exp. Med. 209 (6), 1121-1134. doi: 10.1084/Jem.20120242

Xu, D. H., Cullen, B. D., Tang, M., and Fang, Y. (2019). the Effectiveness of Topical Cannabidiol Oil in Symptomatic Relief of Peripheral Neuropathy of the Lower Extremities. Curr. Pharm. Biotechnol. 21 (5), 390-40. doi: 10.2174/ 1389201020666191202111534

Young-Wolff, K. C., Tucker, L. Y., Alexeeff, S., Armstrong, M. A., Conway, A., Weisner, C., et al. (2017). Trends in Self-Reported and Biochemically Tested Marijuana Use Among Pregnant Females in California From 2009-2016. JAMA 318 (24), 2490-2491. doi: 10.1001/Jama.2017.17225

Conflict of Interest: KG reports grants from Grifols, Cyclerion, and 1910 Genetics, and honorarium from Novartis, Tautona Group, and CSL Behring, outside the submitted work.

The remaining authors declare that the research was conducted in the absence of any commercial or financial relationships that could be construed as a potential conflict of interest.

Copyright (c) 2020 Argueta, Ventura, Kiven, Sagi and Gupta. This is an open-access article distributed under the terms of the Creative Commons Attribution License (CC BY). The use, distribution or reproduction in other forums is permitted, provided the original author(s) and the copyright owner(s) are credited and that the original publication in this journal is cited, in accordance with accepted academic practice. No use, distribution or reproduction is permitted which does not comply with these terms. 